\title{
Erratum to: Predicting Organ Space Surgical Site Infection with a Nomogram
}

Luiz F. de Campos-Lobato • Brian Wells • Elizabeth Wick • Kevin Pronty • Ravi Kiran • Feza Remzi • Jon D. Vogel

Published online: 19 January 2011

(C) 2011 The Society for Surgery of the Alimentary Tract

\section{Erratum to: J Gastrointest Surg} DOI 10.1007/s11605-009-0968-6

An author's name was inadvertently misspelled in this paper, the first author should be:

Luiz F. de Campos-Lobato.

The corrected author list for this paper is:

Luiz F. de Campos-Lobato, Brian Wells, Elizabeth Wick, Kevin Pronty, Ravi Kiran, Feza Remzi and Jon D. Vogel

The online version of the original article can be found at http://dx.doi. org/10.1007/s11605-009-0968-6.

L. F. de Campos-Lobato $\cdot$ K. Pronty $\cdot$ R. Kiran · F. Remzi •

J. D. Vogel $(\bowtie)$

Department of Colorectal Surgery, Cleveland Clinic,

9500 Euclid Avenue A30,

Cleveland, OH 44195, USA

e-mail: vogelj@ccf.org

B. Wells

Department of Quantitative Health Sciences, Cleveland Clinic,

Cleveland, OH, USA

E. Wick

Department of Surgery, Johns Hopkins Hospital,

Baltimore, MD, USA 